\title{
Writing, reflection and learning - an interactive approach
}

\author{
Gina OxBrow \\ Universidad de Las Palmas de Gran Canaria \\ (Departamento de Filología Moderna)
}

Received: 28-03-05 / version accepted: 14-04-05

ISSN: $1697-7467$

\begin{abstract}
Much recent learner-centred research has addressed the role of direct and indirect learning strategies in second language acquisition and production, as well as the value of metacognitive awareness in writing skills development. We shall describe a longitudinal project carried out with first-year Canarian university students focusing on the effect of integrated training in metacognitive and socio-affective strategies applied to EFL writing skills instruction. The use of dialogue journals, which reveal the frequency of metacognitive and socio-affective strategies deployed by our learners and the value of guided written reflection, will also be highlighted as both a quantitative and qualitative research instrument.
\end{abstract}

Key words: learning strategies, strategy training, writing skills, metacognition, dialogue journals

RESUMEN: Mucha investigación reciente ha estado enfocada en el papel que juegan las estrategias directas e indirectas en la adquisición y producción de una segunda lengua, y el valor de metacognición en la expresión escrita. Vamos a describir un proyecto longitudinal realizado con alumnos universitarios de primer curso que investiga el efecto de una formación integrada en estrategias indirectas en el desarrollo de la expresión escrita. Se destacará la utilización de diarios interactivos como instrumento de investigación cuantitativa y cualitativa que revelan tanto la frecuencia de las estrategias de aprendizaje empleadas por los alumnos como el valor de una reflexión guiada.

Palabras clave: estrategias de aprendizaje, formación en estrategias de aprendizaje, expresión escrita, metacognición, diarios de aprendizaje interactivos.

\section{LEARNING TO WRITE IN ENGLISH: INITIAL OBSERVATIONS}

Learning to write well in a foreign language may seem to be a daunting and complex task, especially when viewed solely as a language learning exercise primarily focusing on the accurate manipulation of language or discourse features. Despite much valuable investigation over the last thirty years or more addressing the development of L1 and L2 writing skills ${ }^{1}$

${ }^{1}$ A large body of writing skills research has come from the United States. See Silva and Brine (2004) or Polio (2003) for comprehensive recent overviews. Kroll (1990) also provides a variety of useful insights on L1 and L2 writing research. 
which has had far-reaching practical implications for the writing classroom, it is still somewhat true that traditional approaches to writing instruction often prevail. As a result, writing tasks set in class, or more demanding out-of-class assignments, are often considered by our learners to be demotivating, empty exercises, merely writing for writing's sake, and have little perceived value for either teacher or learner other than the written practice of target language features.

One possible source of the disappointing responses from our learners towards the development of writing skills may be the nature of the writing tasks which they are faced with, which may often appear unrealistic in terms of the teacher's expectations of their linguistic ability or knowledge of their areas of interest as well as the intellectual level of the expected content. Writing activities may also be seen as uninspiring, uncreative or difficult by students, often due to the fact that they are given insufficient guidance or pre-writing input as if writing in a foreign language were an automatic ability present in varying degrees in relation to levels of linguistic proficiency. Motivation is frequently low with writing tasks, which is especially the case when tasks are imposed by the teacher, too often with an evaluatory objective rather than a communicative aim. Written texts become quantitatively focused, accuracy-based exercises, with only a grade to look forward to on their completion, and the potentially highly communicative act of writing in English becomes a solitary pursuit, rather than an interactive exercise.

Negative reactions such as these are typical of our own first-year learners on beginning their university studies in "English Philology" at the Universidad de Las Palmas de Gran Canaria. Although a great deal of valuable learner-centred research focusing on L2 writing skills development has been carried out in a variety of teaching/learning environments (e.g. Bereiter and Scardamalia, 1983; Kroll, 1990; Raimes, 1991; Silva, 1993; Kasper, 1997; Polio, 2003; Silva and Brine, 2004), few of the resulting practical implications (such as process approaches, strategy training, assessment, reformulation procedures, peer editing or teacher feedback) seem to have filtered through to the writing classes these novice writers have received in their previous learning contexts. The problem seems to reside in the fact that there is still often little differentiation between teaching activities for language reinforcement and those which develop the writing skill per se. The longitudinal research project we shall briefly describe here is an attempt to improve and inform the teaching and learning of writing skills in our own context by means of an integrated strategy training programme which has yielded a wealth of insights that our learners themselves have provided with regard to their own learning processes.

\section{TARgET LEARNING CONTEXT: NEEDS AND CONSTRAINTS}

The learning and teaching environment in this particular study is that of a university EFL course corresponding to a compulsory component, 'English Language I', of the fouryear degree course in "English Philology", offered in this case by the University of Las Palmas de Gran Canaria in the Canary Islands, but nevertheless a common learning environment to be found all over Spain. Our instructional context is characterised by various problematic elements, including overcrowded classes, an unsatisfactory amount of contact hours per week (five), mixed levels of proficiency, and little time for our students to devote to individual 
practice and study in view of all the other"more academic" subjects to be passed in the plan of studies for this degree.

The subjects that made up the sample involved in this longitudinal study corresponded to 48 first-year Spanish-speaking English language students with an average age of 18, and mostly recent high-school graduates who were initiating their university studies. The subjects were alphabetically divided into two groups for class sessions, Group A (32 students, 26 female and 6 male) and Group B (16 students, 15 female and 1 male), with their five hours of English language instruction divided into four hours of general English, integrating both grammatical and vocabulary work with skills development and one separate hour specifically for writing skills development.

Inevitably, learners in their first year of university studies arrive with widely varying levels of proficiency and previous experiences of learning, with the level of English of a great majority of first-year students disappointingly low (Coletes Blanco, 1993:53). The 'English Language I' course consists of improving linguistic ability in the target language within all four language skills areas based on a communicative, task-based approach, loosely following a course-book syllabus with the incorporation of a large amount of authentic material, teacher-created tasks and training in language learning strategies. The exit level is upper intermediate (similar to Cambridge ESOL Level 3 First Certificate in English) and formal evaluation takes place at the end of the year by means of written exams in four areas ('Use of English', 'Reading Comprehension', 'Vocabulary', and 'Writing Skills'), with a further speaking/listening test for those candidates who are successful in the written papers.

\section{LANGUAge LEARNING STRATEgIES AND WRITING SKILLS}

It is our experience that skills training sometimes tends to be passed over in favour of more analytic or linguistically-focused language study in such a university context, with learners required to magically become competent in language use, text production and strategies or techniques for learning by themselves. Rubin (1975:44-5) succinctly describes the common tendency of teachers to plough ahead with the lesson:

[...] seemingly with little awareness of what is going on in each student and often without directing the attention of the poorer students to how the successful student arrived at his answer. That is, many foreign language teachers are so concerned with getting the correct answer that they fail to attend to the learning process.

In recent years, the contribution of empirical evidence has highlighted the emerging significance of the learner as an active participant in the learning process (e.g. Skehan, 1998; Wenden, 1991) and learner behaviour, along with those elements that might affect it, has been investigated in a very holistic manner which has encouraged a more learner-centred focus in language teaching methodology (e.g. Tudor, 1996; Nunan, 1991). While many of the factors affecting language learning may be difficult, or even impossible to modify, recent investigation has focused on those variables, such as attitude and motivation, which individual learners are 
able, and should indeed be encouraged, to modify (e.g. Breen, 2001; Dörnyei, 2001). This has given rise to the question of what learners can do independently to facilitate the learning process with respect to those more modifiable characteristics that they are able to influence themselves such as their repertoire of learning strategies which they might be encouraged to extend and exploit further.

Inspired by the seminal 'Good Language Learner' research initiated in the 1970's (Stern, 1975; Rubin, 1975; Naiman et al., 1978), a considerable body of academic research within the two complementary disciplines of Cognitive Psychology and Second Language Acquisition, has brought to the fore the fundamental role played by more tactical elements in the complex process of learning a second/foreign language and achieving communicative competence. One of the resounding conclusions from the many empirical investigation projects that have been carried out is that successful language learners make use of a wide and flexible repertoire of different types of learning strategies (e.g. Cohen, 1998; Oxford et al., 1996; O'Malley and Chamot, 1990; Oxford, 1990). It has been suggested that well-chosen or appropriate learning strategies support learning both directly and indirectly and that these techniques, once isolated and identified, can be taught to those who are less successful, leading to considerable potential for the ongoing development of language skills both inside and outside the classroom. Since we must bear in mind that the ability to exploit appropriate strategies for a variety of learning tasks is not always inherent or automatic, learners often need guidance in how to learn more effectively; linguistic proficiency is seldom achieved without some kind of direction. It is thus the role of those facilitating language development to provide learners with proven effectual ways to learn, catering for a wide range of different learning styles, rather than simply teaching content matter or evaluating progress.

The connotations thrown up by the term 'strategy', despite its military origins, suggest the management of available resources in a planned or carefully orchestrated tactical campaign towards a certain goal, or "a plan, step, or conscious action toward achievement of an objective" in non-adversarial situations (Oxford, 1990:7). However, in the research literature, the concept of language learning strategy has proved difficult to define in a consensual manner (Ellis, 1994:530) since the multitude of definitions that have been proposed are complex and notoriously vague, with the further complication of the hazy differentiation between learner strategies and learning strategies. Cohen (1998:5) provides a useful definition for our purposes:

Second language learner strategies encompass both second language learning and second language use strategies. Taken together they constitute the steps or actions consciously selected by learners either to improve the learning of a second language, the use of it, or both.

Henceforth we shall use the umbrella term learning strategies ${ }^{2}$ since this describes those actions or behaviours which learners resort to in order to make the process of language learning more successful, self-directed, and enjoyable.

${ }^{2}$ Both 'learning' and 'learner' strategies are used in varying ways by different researchers with the current vogue tending towards 'learner strategies' as a reflection of the learner-centred climate reigning in current research (McDonough 1999:2). We shall predominantly use 'learning' strategies in this study as a generic term covering both the aspects of learning and the participation of the learner in the processes described. 
Language learning strategies can be described in general terms as tactics, behaviours, techniques, steps or actions used by students, either consciously or unconsciously, to facilitate, improve or advance their learning, and they may range from cognitive techniques such as structural practice, analysing or note-taking, to metacognitive or learning management techniques such as planning for learning tasks or self-evaluation, as well as to social or affective techniques such as co-operating with others or lowering anxiety (Oxford et al., 1996: 19). It has been found that more successful language learners invariably exploit a wide and flexible repertoire of strategies which involve many aspects of the learners themselves, not just the cognitive (Wenden and Rubin, 1987; O'Malley and Chamot, 1990; Oxford, 1996; Cohen, 1998). Within such a learner-centred approach, the teacher should be encouraged to play an active role by training learners to recognise and exploit effective learning strategies in order to extend their strategy knowledge so that they may strive towards greater autonomy.

Over the last thirty years or so, a considerable range of language learning strategies have been formally discovered and named. A variety of classifications and typologies have been offered in the research literature (e.g. Stern, 1975; Naiman et al., 1978; Rubin, 1981; O' Malley and Chamot, 1990), but for the purposes of this study we shall use Oxford's (1990) well-known comprehensive scheme which embraces 62 different strategies divided into 6 sub-groups: these are memory, compensation, cognitive, metacognitive, social and affective strategies. These subgroups are separated into two major types: direct (memory, cognitive, compensation) and indirect (metacognitive, affective, social) strategies.

It is the latter group, the lesser-investigated indirect strategies, which will form the basis of the present study, with the three strategy types of particular interest in this study corresponding to metacognitive, affective and social strategies. These are classified by Oxford as indirect strategies since they do not directly involve the target language, but instead provide learners with ways to co-ordinate and improve their learning processes. Metacognitive strategies refer to strategies underpinning learning which go beyond the cognitive and which exercise a kind of control over cognition and learning, i.e. those strategies which correspond to planning, monitoring, or evaluating learning, whereas affective strategies are those which help learners regulate or gain better control over their emotions, attitudes and motivations related to language learning. Social strategies are those which involve the social, co-operative elements of learning (see Appendix A for a full list of indirect strategies).

\section{Strategy training Project: AIMS AND IMPlementation}

Our principal research question addressed the effect of integrated training in metacognitive, affective and social learning strategies on our learners' strategy use and repertoire, specifically in this case within the area of writing skills development. We hoped this would enable our learners to enjoy greater autonomy as a means to making their learning more effective, especially since the development of writing skills typically produces a certain amount of anxiety and demotivation and is highly appropriate for the exercising of metacognitive and affective control (Silva, 1993; Kasper, 1997).

Metacognitive strategies are generally considered essential for successful language learning in their executive capacity of organising learning time and co-ordinating the learning process 
by means of centering, planning and evaluating learning. It has also been found that while learners exploit some metacognitive strategies consciously, such as planning or arranging learning, they fail to employ other crucial metacognitive strategies related to, for example, evaluating progress, or seeking practice opportunities (Oxford, 1990:138). Social strategies involving interaction with others, and affective strategies or motivational factors are also highly influential on language learning success or failure, since effective language learners are, according to Oxford (1990:140), often those learners who know how to control their emotions and attitudes towards learning. ${ }^{3}$ In our experience, greater attention has been afforded in both research and instructional contexts, as well as in published materials, to memory, cognitive or compensation strategies, which directly involve the manipulation of the target language. Yet, by providing learners with a wider range of metacognitive and socio-affective strategies, not only will these learners raise their awareness of learning but they will also be better equipped to take control of their own learning processes beyond the confines of the language learning classroom.

Our primary objective in this study was to determine the quantity and types of learning strategies being exploited by university foreign language students in the area of writing skills after integrated training. Secondary objectives corresponded to expanding students' awareness of their own strategy use and adding new strategies to their repertoire, to provide further practice for writing skills development and to encourage greater learner autonomy. We should remember that writing instruction is not merely a question of emphasising and drilling linguistic or metalinguistic concerns or the assembling of a tightly-controlled word puzzle with different components interlocking in multiple ways. Too much emphasis on mechanical concerns may inhibit the fledgling writer and kill both creativity and motivation, fundamental ingredients of successful and meaningful written expression. The interactive and reflective nature of writing also needs to be addressed along with more formal accuracy-based instruction such as outline construction, paragraph analysis and topic sentence isolation. Written expression is, after all, a daunting task in any language and writing well does not come naturally to many. Training is needed and awareness needs to be raised both at instructional and developmental levels.

In particular, we hoped to demonstrate the correlation between metacognitive knowledge and writing proficiency as measured by formal writing examinations, and highlight the relationship between strategic awareness and skills development. In our opinion, metacognitive strategies and socio-affective strategies work in tandem as two distinct strategy types rather than three; although Oxford's classification scheme divides the indirect strategies into the three sub-groups of metacognitive, social and affective, we consider the metacognitive group to warrant more individual attention due to the link with writing development as shown in previous research projects (e.g. Kasper, 1997).

To summarise the strategy training procedure, the initial step we took with regard to the preparation for training was that of the identification and diagnosis of the strategies our learners already used by means of Oxford's "Strategy Inventory for Language Learning" or SILL (1990: 293-300) in order to decide which areas warranted more attention, in accordance with our learners' needs and their learning context, so as to be able to devise an effective

${ }^{3}$ See Arnold (1999) for interesting perspectives on the role of affect in language learning. 
training programme for them; only once we know how our learners are currently learning, can we help them to learn more effectively.

After selecting strategies for training, materials and activities were then prepared for explicit, but gradual integration as strategy training in the execution and practice phase. This involved developing student awareness (e.g. by group discussion, awareness-raising tasks, retrospective writing tasks about previous learning experiences, questionnaires and strategy inventory), followed by the initial presentation of strategies (modelling by teacher, describing or naming strategies and providing rationale for strategy use). The execution and practice phase of the strategy training procedure focused specifically on the development of English Language writing skills in separate instructional sessions (one hour a week) ostensibly devoted to writing activities in contrast to the four hours a week dedicated to general 'Use of English' tasks. This was combined with the integration of explicit training in selected metacognitive, affective and social strategies, including planning, generating ideas, lowering anxiety, cooperative learning, peer editing, peer evaluation, student-generated assignments, seeking practice opportunities, self-monitoring, evaluating learning and evaluation criteria.

In an attempt to deflect attention away from the product rather than the process involved in creating a text and to respond to the gradual progress being made, the students' writing proficiency was evaluated by means of a process of continuous assessment as well as a final essay written in formal examination conditions. Five of the assignments during the year were evaluated as part of their final grade, and learners were required to hand in all planning work and multiple drafts as part of the process of evaluation. Learners were also given the opportunity at different points during the course to select their own topics for writing, at times through group discussion, in order to maintain a learner-centred approach. At the end of the course and before the final examination, all learners handed in a portfolio containing all their written work from the entire year as well as their dialogue journal.

For the evaluation phase data was collected over a period of nine months corresponding to the complete academic year in order to assess the effectiveness of the training programme and indirect strategy use by our subjects by comparing generic pre-course strategy repertoire using Oxford's 'Strategy Inventory for Language Learning' or SILL (1990) and post-course content analysis of their dialogue journals in combination with statistical results from structured questionnaires, which were implemented three times during the strategy training programme. ${ }^{4}$ We also have access to recorded interviews, class notes and recorded class sessions, and both written assignments and final examination scripts for the subjects participating in this study. Detailed class plans were also carefully kept up-to-date in a teaching log to help with the description of the strategy training procedure.

\section{Dialogue journals}

As mentioned above, both groups were invited to write and reflect on their learning in a self-directed interactive dialogue journal with their teacher for the second half of the academic year so as to provide a supplementary, motivating, student-centred activity, as well

${ }^{4}$ The questionnaires have not been included here as the emphasis is this brief summary of our study is on the qualitative data from dialogue journals. 
as research data, in order to contrast with the accuracy-based, objective task of controlled composition writing. The learners would be given prompts for writing, to be done both in class sessions and in their own time. In return, the teacher would reply to the students in their journals by writing approximately the same amount back in order to reward them for their efforts, provide them with written feedback, offer them authentic English to read and provide comprehensible input, respond to their questions or areas of expressed interest and establish meaningful communication. Thus, these guided journals became part of the teaching/learning process as well as being part of the action research project conducted here.

Diaries or dialogue journals provide a much more open, unprompted medium of expression or revealing written reflection and are often left to the learner to control in terms of content and quantity (Matsumoto, 1996; Fedderholt, 1998). By writing in them, the learner probably describes strategies for isolated tasks which are difficult or important, or provides accounts of functional tasks described in context, as well as exploring their language learning experience in general along with other issues relevant to them. This is one of our reasons for combining more restrictive, structured surveys and pre-set questions with largely free, learner-controlled dialogue journals with no explicit correction and only veiled guidance.

Entries typically cover a wide range of issues, including written retrospective verbal reports of the cognitive, metacognitive, affective and social strategies they use in their language learning. By writing about and reflecting on their strategies, learners become more aware of the ones they and their peers use over a period of time and they become "participant observers" (Long 1979, quoted in Oxford et al., 1996:21) in their own learning with the opportunity for self-evaluation and improvement. Journals may be used to discover what is significant to the learners themselves rather than what the teacher perceives their needs or problems to be. In addition, they provide a vehicle for improving and experimenting with written expression as learners are encouraged to write and reflect regularly, a medium of expression which is especially valuable for those learners who do not like to participate orally in class. Above all, affective issues, such as anxiety and motivation, may also come to the fore, as is very much the case in the present study.

The value of written retrospective verbal report in dialogue journals (e.g. Peyton, 1990) is only recently emerging as a research instrument with much potential for strategy research due to the wealth of data which may be elicited, especially of directly unobservable aspects such as self-evaluation or affective factors such as anxiety. Although diaries have been exploited for research into language learning strategies (Oxford et al., 1996; Fedderholt, 1998), dialogue journals between learners and teacher have yet to be used widely as a research tool in formal studies in this area. The potential of students' own written perceptions deriving from guided or free reflection on a variety of issues relevant to them and their own, ongoing learning experience is gradually being realised despite the drawbacks provided by the enormous volume of potentially random recollective, self-report data produced (Mlynarcyzk, 1998; Oxbrow, 2001a, 2001b; Eken, 2001).

\section{RESULTS: FREQUENTLY EXPLOITED STRATEGIES}

The quantitative results obtained from the three structured questionnaires distributed to the learners at different points in the training programme showed an increase both in metacognitive awareness and strategy repertoire, and this was further corroborated in the 
subsequent analysis of the dialogue journals. Evidently, the strategies which were reported in the questionnaires were very much guided and influenced by the content of the reporting instruments, hence the need to contrast and triangulate with open-ended introspective reports in the learner-directed journals.

Data from journals can be interpreted either in an analytical, quantitative manner or in a more global, narrative way (Oxford et al., 1996:20); quantitative calculations alone say little about the social or affective factors involved in learning. We principally examined strategy use using a qualitative approach in the case of the analysis of learner journals, although a quantitative study using content analysis procedures for calculating for number and type of strategies as reported by students was also carried out using Oxford's (1990) 62item classification scheme.

The quantitative results obtained from content analysis of the journals revealed, in most cases, a well-developed repertoire of strategies reported with varying frequency. As we can see from the

SILL results corresponding to strategy use at the outset of the training period, the indirect strategy group accounts for just over half of the reported initial strategy repertoire, with a total percentage value of $53 \%$, and the direct group slightly less at $47 \%$ (Figure 1). This clearly contrasts with the final data: the highest percentage of strategies reported in the data, almost two thirds of the total value, corresponded to indirect (64\%) learning strategies, with just over a third relating to direct strategies (36\%) (Figure 2).

\section{Figure 1}

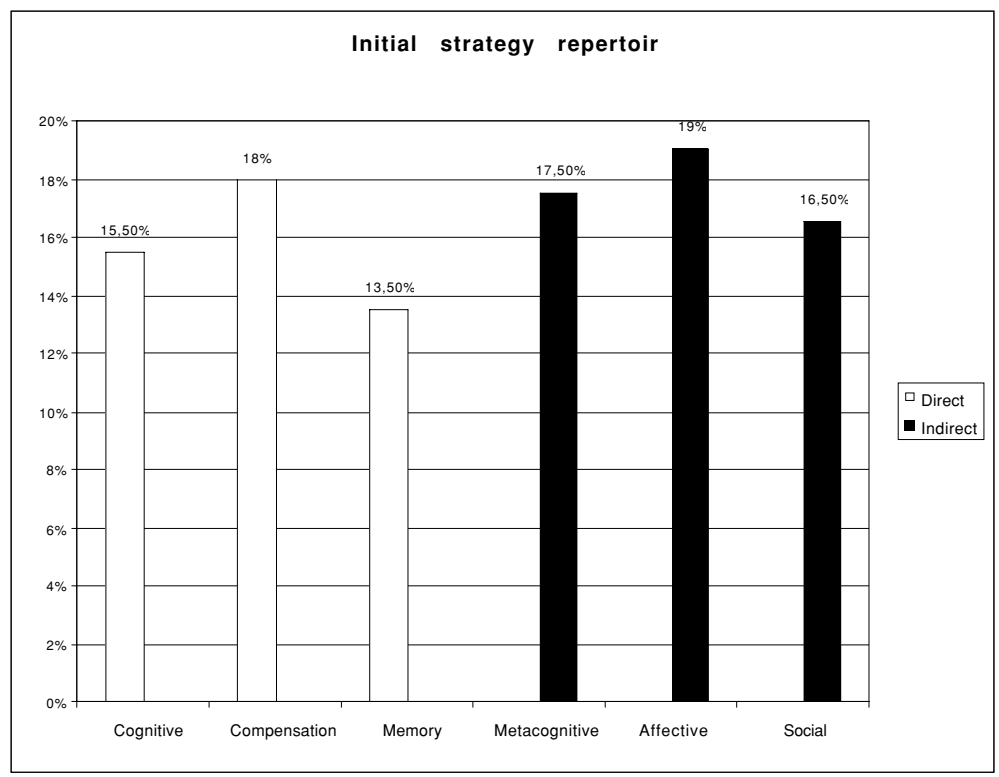


Figure 2

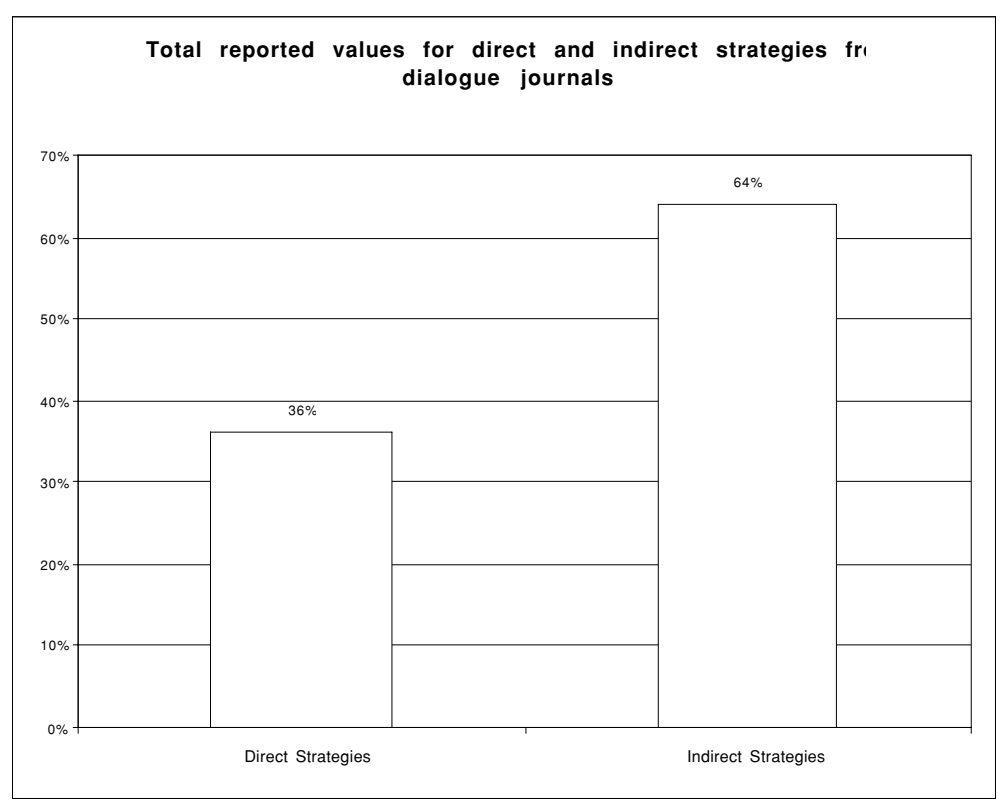

With reference to particular strategy types (see Figure 3), the highest scoring group proved to be that of metacognitive strategies (31\%) followed by affective strategies (20\%) which showed an almost identical value with cognitive strategies (19\%). This is an encouraging result since this type of strategy was the one which had enjoyed the principal focus in our training programme. A range of metacognitive strategies were mentioned in all diaries, and within the metacognitive group, frequently appearing strategies were those corresponding to the sub-group of Arranging and Planning Learning (IB), ${ }_{5}^{5}$ particularly those of setting goals and objectives (IB3), identifying the purpose of a language task (IB4), planning for a language task (IB5) and seeking practice opportunities (IB6). More significantly, we found a large number of examples for the sub-group Evaluating Your Learning (IC) which includes the strategies of self-evaluation (IC1) and self-monitoring (IC2), tactics which were previously little used by our subjects since, as Fedderholt (1998: 5) points out, learners usually have little practice in either technique and often have an inaccurate idea of their own abilities. These strategies of evaluating learning and self-monitoring formed part of the training programme as they were explicitly encouraged in the teacher's entries in the dialogue journals and subsequently adopted by our subjects as evidenced in their ongoing written reflection.

${ }^{5}$ See Appendix A for the numbering of strategies. 
Figure 3

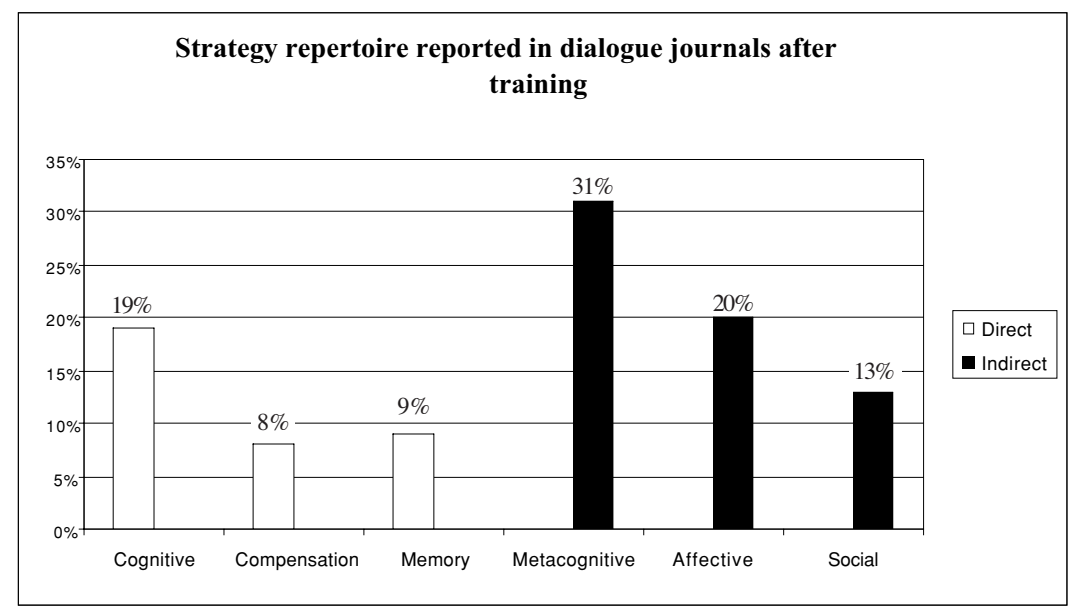

This differs greatly from previous learning strategy studies (O'Malley and Chamot, 1990; Oxford et al., 1996) in which the most frequently appearing learning behaviours corresponded to memory and cognitive strategies, with a limited selection of metacognitive strategies, and very rare mention of affective and social strategies. The relatively high mention of affective strategies also contrasts with findings in other studies (Oxford et al., 1996:25), highlighting in our context of writing skills development the importance of affective factors such as anxiety and motivation, with the most often repeated strategies in this group corresponding to those of making positive statements (IIB1) and discussing your feelings with someone else (IIC4). It goes without saying that the strategy of writing a language learning diary (IIC3) was the most effective in these two groups.

The qualitative data we have access to from the journals were analysed from two perspectives: (a) the increase in writing skills proficiency and fluency improvement and (b) learning strategy awareness. This free practice also demonstrated that our learners never seemed to be at a loss for ideas, a frequent obstacle in formal composition writing. One of the values of this study has been the fresher, clearer writing voice discovered by our learners as they lost the anxiety associated with being formally evaluated. They also seemed to have discovered by means of such autonomous writing practice that the skill of writing involves much more than simply constructing lists of accurate sentences which need to fit into a fixed, pre-established format. The final examination results speak for themselves: in Group A 66\% and in Group B $88 \%$ passed the final writing skills examination at the first attempt. ${ }^{6}$

${ }^{6}$ These results compared favourably with a third group (Group C) of first-year learners in 'English Language I' receiving similar instruction but who did not participate in the integrated strategy training described here. This group had a different teacher and a different timetable (afternoon shift). 
It is highly significant to discover that the most revealing source of data relating to the evaluation of the effectiveness of the strategy training implemented in this study has been the learners' retrospective self-reporting in the dialogue journals, an autonomous, awarenessraising activity that is also characterised by genuine written communication between teacher and learner in the target language which has also provided valuable reflective writing practice for the learners involved. In fact, the journals proved to be much more than a mere instrument for data collection in research on language learning strategy use; they were also an effective technique in themselves for strategy training, both on a metacognitive level, by encouraging written reflection about the learning process, and on an affective level, by lowering anxiety, raising motivation and providing the opportunity to share thoughts, feelings and worries (as well as on a social, communicative level as described above). Consequently, journals seem to us to constitute an instrument worthy of further investigation in research focusing on strategy use in the area of writing skills.

We must not forget also the didactic value of such an autonomous writing activity, shown in learners not only using dictionaries or other resources to look for required vocabulary or recycling lexis recently practised in class session but also acquiring language from the teachers' own language: in the words of one learner:

This way of writing English is very useful for me. I'll give you an example: I notice that you use sometimes the expression "It sounds like..." and I've never seen this before, so I ask a friend for its meaning and she told me it. So now when I have the opportunity I will use it.

Motivation is also raised considerably: in the words of another learner:

Have you ever thought what we feel when you return our diaries to us? Its almost indescribable. It's like a mixture of pride and curiosity (An English native writes you!).

On a qualitative level not only was the progress in written expression highly noticeable, with journal entries becoming ever more fluent and ambitious even in weaker students, but this practice technique was also viewed as extremely positive and motivating by the students themselves. For most of the participating subjects, this was an innovative and experimental fluency exercise in contrast with more accuracy-based work, and they were encouraged in this way to think more about their learning, pleased to discover the teacher's interest in their learning trajectory and not just their proficiency or ability, as is often the case. Students always seemed motivated to write about problems with writing or the strategies they use in all four skills areas. Being at a loss for ideas is a frequent obstacle in formal composition writing, which is a familiar experience when obliged to write, but this was not the case in free practice of this kind.

It is undeniable that these dialogue journals contributed especially to the development of all three types of indirect strategies in a motivating, contextualised manner. The success of this particular method in the development of learning strategies relies not only on the invaluable opportunity for genuine, communicative practice (with a written record for the learner), but also on the lowering of the affective filter, the freedom of subject matter, fewer 
restrictions (as another learner points out: " [...] I hate compositions, they kill my freedom in writing and that makes me feel like a robot, and I'm not a machine[...]"), and valuable comprehensible teacher input, at times with unobtrusive correction in the guise of the reformulation of ambiguous or confusing expression.

One of the values of this study has been the discovery of the fresher, clearer writing voice discovered by our learners as they lose the fear of being graded or evaluated formally, now unafraid to express opinions or disagree with a set writing model or frequently unattainable ideal which is often the case with more formal composition writing. Their experience of teacher feedback or evaluation of formal composition writing had in the main been limited to a grade and a perfunctory, largely unread note, usually written in justification of the grade awarded in relation to the evaluated piece of work's conformity to a previously presented writing model, with any originality or creativity discouraged. Very seldom are there constructive pointers for future improvement or further practice opportunities. In interactive journals, the undeniably social practice of reading and writing takes place through the medium of learnercontrolled discourse along with contextual practice of acquired grammatical, functional and lexical knowledge.

\section{Practical implications}

Language learning strategies seem to be important tools for the active, self-directed involvement needed for developing second language communicative ability. The training in metacognitive, affective and social strategies in the current project seems to have been highly successful, and has greatly contributed to improved proficiency in written English. Thus, strategy training should include preparation in not only direct (cognitive) learning strategies, but also in indirect (metacognitive, affective and social) strategies, especially since the latter category is all too often passed over in favour of more cognitively demanding learning activities. Teachers are often unaware of or mistaken about their students' strategy preferences (Oxford et al., 1996:19), and we should remember that language learning strategies may be highly beneficial, and maximum benefit may be derived, only if and when both teachers and students are aware of their utility and pay attention to them.

We hope to have demonstrated here the important role of indirect learning strategies, and especially metacognitive knowledge, in the successful development of writing skills, evidenced especially in the valuable autonomous practice afforded by the writing of dialogue journals or learning diaries in the target language. Successful L1 writers have been found to delay questions of linguistic accuracy during the drafting process and it is often true that language learners who display inadequate writing skills show a premature fixation with editing concerns and accuracy from the outset. This suggests that learning to write should perhaps incorporate more interactive activities for fluency development, with a focus on both accuracy and fluency fundamental in writing instruction, since it is significant that the gradual creation of meaning in the search for ideas can also generate language. University learners still need to develop a high degree of automaticity in a multitude of linguistic aspects, and it is here that fluency activities such as journals can offer self-directed skills practice in combination with more formal instruction in the linguistic and rhetorical features of written texts. In this way, writing 
might become more positively viewed by learners stifled in academic environments: compare the following comment from a learners' journal with those reactions cited from the beginning of the course:

I have recently noticed that I have improved on my written English. It must be because I have started to write freely, to write about what I want when it suits me. There are no barriers or limits to express myself and I enjoy doing this [...] there are certain moments in which I prefer writing to speaking.

Additionally, by means of training learners to view composition as a process using multiple draft techniques characteristic of the 'process approach', our subjects were engaged in an act of writing as discovery as a way to create meaning which provides them with the time and opportunity to tackle linguistic problems more effectively than in the traditional one-draft approach in which problems are often pointed out but hardly ever solved. The connection between writing and learning has been widely documented in different content areas, with the act of writing resembling a discovery process and a way to explore, generate and connect ideas or experiences as well as to change preconceived notions or attitudes. We can also learn a great deal from our learners' perceptions: we now have an enormous amount of data providing us with many future areas for our own research which include the use of dialogue journals for both fluency development and guided reflection, peer evaluation procedures, language learning anxiety, learners' reactions to teacher feedback, reformulation as a correction technique, the evaluation of writing skills and the classification of indirect strategies.

It would appear that diaries or journals have a great deal of potential for the investigation of learning strategies and learning preferences of second language students (Nunan, 1992:124). As well as being a mine of information for the teacher/researcher and providing insights into the teaching/learning process which can only improve learning, keeping a language learning diary or writing regularly in a dialogue journal is a way of developing student awareness of their own strategy use and fosters active personal attention to strategy potential as well as enabling learners to forge ahead in their quest for autonomy. It provides the necessary space for them to discover and share a wide range of strategies with a supportive reader: the more successful learners can, in this study, be seen to have acquired the strategies, attitudes and knowledge that allow them to use these appropriately and independently of a teacher.

Language learning is a complex process which we will probably never be able to completely unravel. Yet learners and teachers can derive maximum benefit from language learning strategies when both are aware of and pay attention to them: in this way, the evaluation of learning shifts emphasis from the product to the process. Socio-affective strategies appear to have considerable value in the development of written expression in combination with more cognitive concerns. Metacognitive strategies by their very nature involve thinking about the learning process, monitoring one's production and evaluating learning, so they are naturally well suited to reflective writing practice in dialogue journals where students are not only learning to write: they are, after all, writing to learn. 


\section{Bibliography}

Arnold, J. (1999). Affect in Language Learning. Cambridge: Cambridge University Press.

Bereiter, C. and Scardamalia, M. (1987). The Psychology of Written Composition. New Jersey: Erlbaum.

Breen, M. (2001). Learner Contributions to Language Learning. Harlow: Longman.

Cohen, A. (1998). Strategies in Learning and Using a Second Language. Harlow: Longman.

Cohen, A.and Scott, K. (1996). "A Synthesis of Approaches to Assessing Language Learning Strategies" en Oxford, R. (ed.) Language Learning Strategies around the World: CrossCultural Perspectives (Technical Report 13). Second Language Teaching and Curriculum Center: University of Hawai'i Press, 89-106.

Coletes Blanco, A. (1993). "EFL Courses in the English Philology Syllabus: A Proposal for Basic Modular Design", en Revista Alicantina de Estudios Ingleses, 6: 51-62.

Dörnyei, Z. (2001). Teaching and Researching Motivation. Harlow, Essex, UK: Longman.

Eken, A.N. 2001. "An Inner Journey” en English Teaching Professional, 19: 48-50.

Ellis, R. (1994). The Study of Second Language Acquisition. Oxford: Oxford University Press.

Fedderholt, K. (1998). "Using Diaries to Develop Language Learning Strategies." The Language Teacher Online, 22, 4: <http://langue.hyper.chubu.ac.jp/jalt/pub/ttt/98/apr/ fedderholdt.html>.

Ferris, D. (1997). “The Influence of Teacher Commentary on Student Revision”, en TESOL Quarterly, 31, 2: 315-339.

Kasper, L. (1997). "Assessing the Metacognitive Growth of ESL Student Writers", en TESL EJ, 3, 1,A1. <http://www.writing.berkely.edu/TESL-EJ/ej09/al.html>.

Kroll, B. (ed.) (1990). Second Language Writing. Cambridge: Cambridge University Press.

McDonough, S. (1999). "Learner Strategies" en Language Teaching, 32, 1: 1-18.

Matsumoto, K. (1996). "Introspection, Verbal Reports and Second Language Learning Strategy Research", en Canadian Modern Language Review, 50: 363-386.

Mlynarczyk, R. (1998). Conversations of the Mind: The Uses of Journal Writing for SecondLanguage Learners. New Jersey: Erlbaum.

Naiman; N., Fröhlich, M., Stern, M. and Todesco, A. (1978). The Good Language Learner. Toronto: Ontario Institute for Studies in Education.

Nunan, D. (1992). Research Methods in Language Learning. Cambridge: Cambridge University Press.

Nunan, D. (1991). The Learner-Centred Curriculum. Cambridge: Cambridge University Press.

O'Malley, J. M., and Chamot, A. (1990). Learning Strategies for Second Language Acquisition. Cambridge: Cambridge University Press.

Oxbrow, G. (2002). "Let Them Tell Us: Learner Perspectives on Strategic Approaches", en S. Bravo Utrera (ed.), Estudios de Filología Moderna y Traducción en los Inicios del Nuevo Milenio: Universidad de Las Palmas de Gran Canaria (CD Rom).

Oxbrow, G. (2001a). "Silent Dialogues: The Use of Journals for Strategy Training" en Karlsson, L., Kjisik, F. y Nordlund, J. (eds.), All Together Now. Helsinki: University of Helsinki Language Centre, 173-184.

Oxbrow, G. (2001b). "Writing to Learn: The Use of Dialogue Journals for Developing Written Communication", en Team, 1: 54-56

Oxbrow, G. (1999). "Towards Greater Autonomy: Training in Metacognitive and Affective Learning Strategies Applied to Writing Skills in a University Context", en Revista Canaria de Estudios Ingleses, 38: 89-108.

Oxford, R. (2005). Teaching and Researching Language Learning Strategies (ALIA). London: Longman. Forthcoming. 
Oxford, R. (1990). Language Learning Strategies: What Every Teacher Should Know. New York: Newbury House.

Oxford, R (ed.) (1996). Language Learning Strategies around the World: Cross-Cultural Perspectives (Technical Report 13). Second Language Teaching and Curriculum Center: University of Hawai'i Press.

Oxford, R., Lavine, R., Felkins, G., Holloway, M., and Saleh, A.. (1996). "Telling their Stories: Language Students Use Diaries and Recollection”, en Oxford, R. (ed.) Language Learning Strategies around the World: Cross-Cultural Perspectives (Technical Report 13). Second Language Teaching and Curriculum Center: University of Hawai'i Press, 19-34.

Peyton, J.K. (ed.) (1990). Students and Teachers Writing Together: Perspectives on Journal Writing. Alexandria, VA: Teachers of English to Speakers of Other Languages.

Polio, C. (2003). "Research on Second Language Writing: An Overview of What We Investigate and How" en Kroll, B. (ed.), Exploring the Dynamics of Second Language Writing, Cambridge: Cambridge University Press, 35-65.

Raimes, A. (1991). "Out of the Woods: Emerging Traditions in the Teaching of Writing", en TESOL Quarterly, 25, 3: 407-430.

Rubin, J. (1981). “Study of Cognitive Processes in Second Language Learning”, en Applied Linguistics, 11: $117-31$.

Rubin, J. (1975). “What the 'Good Language Learner' Can Teach Us”, en TESOL Quarterly, 9, 1: 41-51.

Silva, T. (1993). "Towards an Understanding of the Distinct Nature of L2 Writing", en TESOL Quarterly, 27, 4: 657-677.

Silva, T and Brine, C. (2004). "Research in Teaching Writing" en Annual Review of Applied Linguistics, 24: 70-106.

Skehan, P. (1998). A Cognitive Approach to Language Learning. Oxford: Oxford University Press.

Stern. H. (1975). "What Can We Learn from the Good Language Learner?", en. Canadian Modern Language Review, 31: 304-318.

Tudor, I. (1996). Learner-Centredness as Language Education. Cambridge: Cambridge University Press.

Wenden, A. (1991). Learner Strategies for Learner Autonomy. Hemel Hempstead: Prentice Hall.

Wenden, A. and Rubin, J. (1987). Learner Strategies in Language Learning. Hemel Hempstead: Prentice Hall. 


\section{APPENDIX A \\ INDIRECT LANGUAGE LEARNING STRATEGIES (OXFORD 1990: 20-21) \\ (Metacognitive, Affective and Social Strategies)}

\section{Metacognitive strategies}

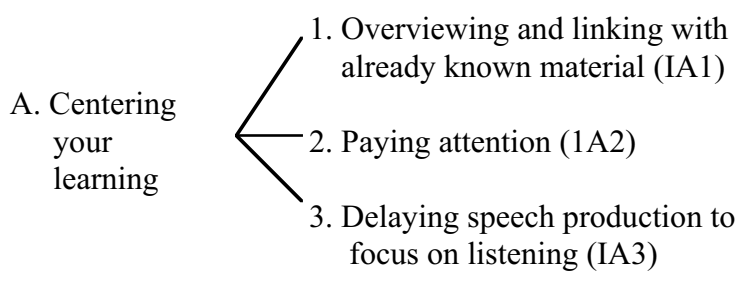

1. Finding out about language

learning (IB1)

2. Organising (1B2)

B. Arranging and planning

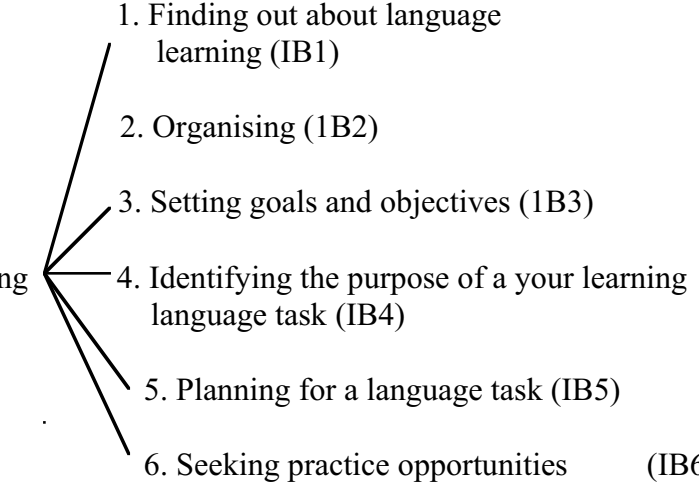

C. Evaluating 1. Self-monitoring (IC1)

2. Self-evaluating (IC2) 
II. Affective strategies
B. Encouraging yourself

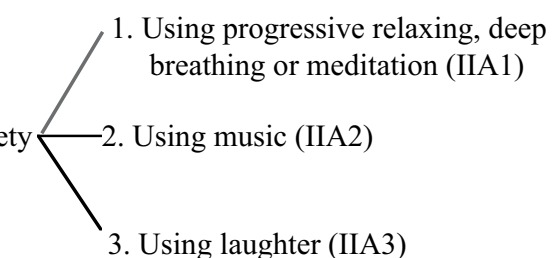

3. Using laughter (IIA3)

1. Making positive statements (IIB1)

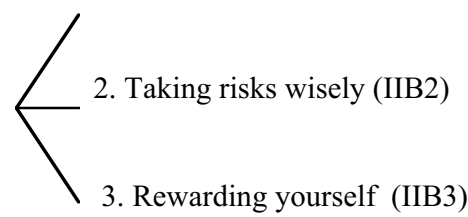

1. Listening to your body (IIC1)

C. Taking your emotional temperature

2. Using a checklist (IIC2)

3. Writing a language learning diary (IIC3)

4. Discussing your feelings with someone else (IIC4)

1. Asking for clarification (IIIA1)

A. Asking questions

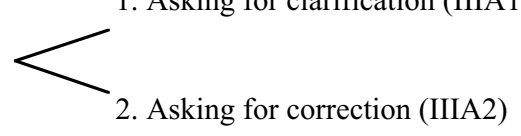

III. Social strategies
B. Cooperating with others

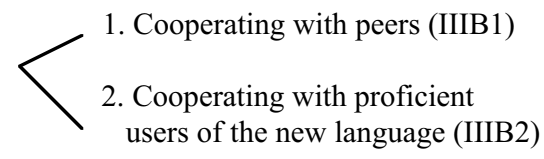

C. Empathizing with others

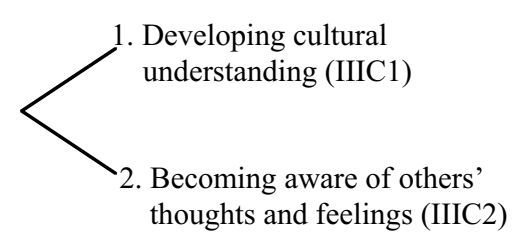

